\title{
Evaluation of Preemptive Effect of Epidural S(+)-Ketamine for Hysterectomy: Plasmatic Concentrations of Interleukins
}

\author{
Elismar Paulo Azevedo Silva ${ }^{1}$, Rioko Kimiko Sakata, TSA 2, João Batista Santos Garcia, TSA ${ }^{3}$, \\ Reinaldo Salomão ${ }^{4}$, Adriana Machado Issy, TSA 5
}

Summary: Silva EPA, Sakata RK, Garcia JBS, Salomão R, Issy AM - Evaluation of Preemptive Effect of Epidural S(+)-Ketamine for Hysterectomy: Plasmatic Concentrations of Interleukins.

Background and objectives: Some studies showed that ketamine inhibits the production of cytokines. The objective of this study was to evaluate the preemptive analgesic effect of epidural S(+)-ketamine in hysterectomy and plasmatic cytokines (IL-6, TNF- $\alpha$ and IL-10).

Method: A double-blinded study with 29 patients was conducted. Patients in Group 1 received $13 \mathrm{~mL}$ of $0.25 \%$ bupivacaine with $25 \mathrm{mg}$ of $\mathrm{S}(+)$ ketamine 30 minutes before surgical incision and $15 \mathrm{~mL}$ of saline solution via the epidural route 30 minutes after. Patients in Group 2 received $15 \mathrm{~mL}$ of saline solution 30 minutes before the surgical incision, followed by $13 \mathrm{~mL}$ of $0.25 \%$ bupivacaine with $25 \mathrm{mg}$ of $\mathrm{S}(+)$-ketamine $30 \mathrm{minutes}$ after. Postoperative analgesia was made with epidural bupivacaine and fentanyl. Dipyrone $1 \mathrm{~g}$ was used whenever required. The following paramenters were evaluated: concentration of cytokines, intensity of pain, time of first request of analgesic and total quantity of analgesic used.

Results: Time for the first request for analgesics was 61.5 minutes in Group 1 and 69.0 in Group 2, without difference between these groups. There was no difference for total dose of fentanyl used in Group $1(221.4 \mu \mathrm{g})$ and Group $2(223.3 \mu \mathrm{g})$. A similar analgesic effect was obtained in both groups, except in T12 (Group $1=2.4 \pm 3.2$; Group $2=5.5 \pm 3.4$ ). No differences in concentration of cytokines were observed.

Conclusions: The epidural injection of $25 \mathrm{mg} \mathrm{S}(+)$-ketamine before incision reduced the pain intensity only 12 hours after surgical incision and did not alter concentration of cytokines.

Keywords: Ketamine; Analgesia; Anesthesia, Epidural; Cytokines; Hysterectomy.

@2012 Elsevier Editora Ltda. All rights reserved.

\section{INTRODUCTION}

The stimulus of surgical trauma provokes peripheral and central sensitivity, with modification of neurons and resulting in allodynia, hyperalgesia and increase of postoperative pain intensity ${ }^{1}$. It also causes increase in the concentrations of cytokines ${ }^{2,3}$.

Pro-inflammatory cytokines (TNF- $\alpha$, IL-1, IL-6, IL-8) indirectly modulate pain through the release of substances like nitric oxide, oxygen free radicals, prostaglandins, and excitatory amino acids from microglia and astrocytes, inducing peripheral and central sensitivity and hyperalgesia ${ }^{4}$.

Received from Universidade Federal de São Paulo (UNIFESP), Brazil.

1. Anesthesiologist, Specialization in Pain, Universidade Federal de São Paulo (UNIFESP) 2. PhD; Pain Sector Coordinator, UNIFESP

3. PhD, Professor, Universidade Federal do Maranhão; President of the Brazilian Society for Pain Study (SBED)

4. PhD, Professor Infectology, UNIFESP

5. PhD, UNIFESP

Submitted on March 24, 2011

Approved May 19, 2011.

Correspondence to:

Dra. Rioko K Sakata

Rua Tres de Maio 61 apto 51

Vila Clementino

04044020 - São Paulo, SP, Brazil

E-mail: riokoks.dcir@epm.br
NMDA receptors have an important role in processing pain. The activation of these receptors by excitatory neurotransmitters, especially glutamate, is essential to the development of central sensitivity and amplification of pain response ${ }^{1}$.

Some drugs have been investigated to prevent or modify these alterations in the central nervous system. Ketamine is an antagonist of NMDA receptors and the $\mathrm{S}(+)$-ketamine isomer is more powerful than the racemic drug and causes less adverse effects ${ }^{5-10}$. Although many studies have used ketamine, its preemptive effect is controversial ${ }^{11-13}$. There is not much information available about administration of epidural ketamine and attenuation of inflammatory response. In a study, a low dose of epidural ketamine did not promote prevention of chronic pain after thoracotomy ${ }^{14}$.

The objective of this study was to evaluate the preemptive analgesic effect and repercussions of epidural $\mathrm{S}(+)$-ketamine on plasmatic concentrations of IL-6, IL-10 and TNF- $\alpha$ in patients undergoing hysterectomy.

\section{METHOD}

A prospective, double-blinded, randomized study was conducted in 29 patients aged between 18 and 60 years, ASA physical status I or II, undergoing abdominal hysterectomy. The study obtained the approval by the Ethics Committee in Research and the patients signed the informed consent 
form. The exclusion criteria were the following: infection in the puncture site, coagulation disorders, hypertension, cancer, psychiatric, cardiac or hepatic disease and analgesic use in the week prior to surgery.

Patients were randomly divided into two groups. The investigator in charge of the evaluation did not know if the patient received the association of bupivacaine and $\mathrm{S}(+)$-ketamine 30 minutes before or after the surgical incision until the end of study. A physician prepared the solution in the same volume and gave it to the anesthesiologist, who did not know its content.

Oral diazepam $(10 \mathrm{mg})$ was administered one hour before the anesthesia. The epidural catheter was kept to control postoperative pain. General anesthesia was induced with propofol (2.5 mg. $\left.\mathrm{kg}^{-1}\right)$ and intubation was carried out with rocuronium (0.5 mg.kg-1). Anesthesia was kept with isoflurane/oxygen. Neither nitrous oxide nor opioids were administered.

Group 1 patients received $13 \mathrm{~mL}$ of $0.25 \%$ bupivacaine without vasoconstrictor via the epidural route associated with $25 \mathrm{mg}$ of $\mathrm{S}(+)$-ketamine in $2 \mathrm{~mL}$ of saline solution, 30 minutes before the surgical incision, followed by $15 \mathrm{~mL}$ of saline solution 30 minutes after. Group 2 patients received $15 \mathrm{~mL}$ of saline solution 30 minutes before the surgical incision, followed by $13 \mathrm{~mL}$ of $0.25 \%$ bupivacaine without vasoconstrictor, plus $25 \mathrm{mg}$ of $\mathrm{S}(+)$-ketamine in $2 \mathrm{~mL}$ of saline solution 30 minutes after the surgical incision.

Blood samples were collected to measure cytokines on the following moments: before the surgical incision (M0), three (M3), six (M6), 12 (M12) and 24 hours (M24) after the surgical incision. Blood was collected on EDTA tubes and centrifuged at $3.000 \mathrm{rpm}$ for 15 minutes. Plasma was stored at $-70^{\circ} \mathrm{C}$ until the moment of analysis. Cytokine levels were determined by ELISA (PharMingen, EUA). All values were reported as picograms per milliliter. The variation coefficients of the immunoessay kits ranged from $5 \%$ to $10 \%$.

Postoperative analgesia was carried out with $4 \mathrm{~mL}$ of $0.25 \%$ bupivacaine associated with $1 \mathrm{~mL}$ of epidural fentanyl $(50 \mu \mathrm{g})$ in bolus according to patients' request with a minimum interval of four hours. To those patients who kept pain score $\geq 3$, $1 \mathrm{~g}$ of intravenous dipyrone was used to complement analgesia. The evaluated parameters were the following: intensity of pain, time to request analgesics for the first time, total quantity of analgesics used within $24 \mathrm{~h}$ and plasmatic concentrations of cytokines. Pain intensity was evaluated by a numerical scale (from 0 to 10 ) in the following moments: arousal state (M0), and six (M6), 12 (M12), 18 (M18) and 24 hours (M24). Side effects were registered.

The number of patients was calculated based on the hypothesis that the difference in pain relief in the group that receiving ketamine before incision would be at least $20 \%$. In order to have a $95 \%$ chance to detect this difference at a level of significance $(p<0.05)$, the number of patients calculated by group was 14 and data were analyzed by the Student's $t$ test (age, weight, height, BMI) and Mann-Whitney test (duration of surgery, intensity of pain, plasmatic concentration of IL6, IL10 and TNF- $\alpha$ ). A p-value $\leq 0.05$ was considered significant. Results were expressed as average $\pm \mathrm{SD}$, and with a confidence interval $(\mathrm{Cl})$ of $95 \%$.

\section{RESULTS}

No differences in age, weight, height, body mass index and duration of surgery were observed between both groups (Table I).

Time to the first request of analgesic complementation ranged from 0 to 150 minutes (average: $61.5 \pm 14.2$ ) in Group 1 and from 0 to 210 minutes (average: $69.0 \pm 19.4$ ) in Group 2 , without significant difference between groups ( $p=1$; MannWhitney test). There was no difference in the total dose of epidural fentanyl for postoperative analgesia between Group $1(221.4 \pm 67.1 \mu \mathrm{g})$ and Group $2(223.3 \pm 49.5 \mu \mathrm{g})(\mathrm{p}=0.89$; Mann-Whitney test).

There was no difference in pain intensity except in $\mathrm{M} 12$, when pain score was lower than in Group 2 (Table II).

No significant difference was observed in the concentrations of IL-6, IL-10 and TNF- $\alpha$ between both groups at the investigated moments (Table III).

The side effects observed during the study were the following: vomiting (Group $1=21 \%$ and Group $2=6.6 \%$ ) and hypotension (Group $1=14 \%$ and Group $2=20 \%$ ). Agitation was observed during the immediate postoperative period in a patient from Group 1.

Table I - Demographic Data and Duration of Surgery

\begin{tabular}{|c|c|c|}
\hline Parameters & Group $1(n=14)$ & Group $2(n=15)$ \\
\hline Age (years) ${ }^{a}$ & $43.4 \pm 1.1$ & $42.9 \pm 1.1$ \\
\hline Weight $(\mathrm{kg})^{\text {a }}$ & $62.1 \pm 2.3$ & $65.1 \pm 3.0$ \\
\hline Height $(\mathrm{cm})^{a}$ & $158.7 \pm 1.5$ & $159.5 \pm 1.0$ \\
\hline $\mathrm{BMI}\left(\mathrm{kg} \cdot \mathrm{m}^{-2}\right)^{\mathrm{a}}$ & $24.7 \pm 1.0$ & $25.5 \pm 1.0$ \\
\hline $\begin{array}{l}\text { Duration of surgery } \\
\text { (min) ca }\end{array}$ & $164.6 \pm 18.3$ & $179.3 \pm 21.7$ \\
\hline
\end{tabular}

Group 1: before incision; Group 2: after incision; BMI: body mass index; aStudent's $t$ test, bMann-Whitney test.

Table II - Intensity of Pain (95\% Cl)

\begin{tabular}{llll}
\hline & Group 1 $(\mathbf{n}=14)$ & Group 2 $(\mathbf{n}=\mathbf{1 5})$ & $\mathbf{p}$ \\
\hline $\mathrm{M}_{0}$ & $2.3 \pm 3.6(0.2-4.4)$ & $3.0 \pm 4.5(0.7-5.2)$ & 0.7723 \\
$\mathrm{M}_{6}$ & $1.4 \pm 2.2(0.06-2.6)$ & $2.7 \pm 3.2(0.9-4.5)$ & 0.2617 \\
$\mathrm{M}_{12}$ & $2.4 \pm 3.2(0.5-4.2)$ & $5.5 \pm 3.4(3.6-7.4)$ & $0.0418^{*}$ \\
$\mathrm{M}_{18}$ & $1.9 \pm 1.9(0.8-3.0)$ & $3.1 \pm 3.4(1.2-4.9)$ & 0.4676 \\
$\mathrm{M}_{24}$ & $1.4 \pm 2.5(-0.06-2.8)$ & $2.0 \pm 3.1(0.3-3.7)$ & 0.5198 \\
\hline
\end{tabular}

Group 1: before incision; Group 2: after incision; $\mathrm{M}_{0}$ : arousal, $\mathrm{M}_{6}, \mathrm{M}_{12}, \mathrm{M}_{18}, \mathrm{M}_{24}: 6,12,18$, and $24 \mathrm{~h}$ after arousal; Mann-Whitney test. 
Table III - IL-6, IL-10 and TNF- $\alpha$ Concentrations (95\% CI)

\begin{tabular}{|c|c|c|c|c|c|c|}
\hline & \multicolumn{2}{|l|}{ IL-6(pg.mL-1) } & \multicolumn{2}{|l|}{ IL-10 (pg.mL-1) } & \multicolumn{2}{|l|}{ TNF- $\alpha$ (pg.mL-1) } \\
\hline & Group $1(n=14)$ & Group $2(n=15)$ & Group $1(n=14)$ & Group $2(n=15)$ & Group $1(n=14)$ & Group $2(n=15)$ \\
\hline $\mathrm{M}_{0}$ & $\begin{array}{l}6.6 \pm 12.9 \\
(-0.9-14.0)\end{array}$ & $\begin{array}{l}7.2 \pm 11.2 \\
(0.8-13.7)\end{array}$ & $\begin{array}{l}32.4 \pm 58.6 \\
(-1.5-66.2)\end{array}$ & $\begin{array}{l}85.5 \pm 150.4 \\
(2.2-169.0)\end{array}$ & $\begin{array}{l}106.0 \pm 94.8 \\
(51.3-160.8)\end{array}$ & $\begin{array}{l}198.7 \pm 388.2 \\
(-16.5-414.0)\end{array}$ \\
\hline $\mathrm{M}_{3}$ & $\begin{array}{l}36.7 \pm 50.0 \\
(7.7-65.5)\end{array}$ & $\begin{array}{l}48.0 \pm 57.3 \\
(17.3-80.7)\end{array}$ & $\begin{array}{l}45.0 \pm 41.0 \\
(21.2-68.6)\end{array}$ & $\begin{array}{l}93.0 \pm 152.6 \\
(8.4-177.5)\end{array}$ & $\begin{array}{l}121.1 \pm 67.7 \\
(82.0-110.2)\end{array}$ & $\begin{array}{l}244.2 \pm 606.1 \\
(-91.5-580.0)\end{array}$ \\
\hline$M_{6}$ & $\begin{array}{l}53.3 \pm 26.2 \\
(28.4-56.7)\end{array}$ & $\begin{array}{l}86.4 \pm 64.7 \\
(50.6-122.2)\end{array}$ & $\begin{array}{l}41.1 \pm 50.0 \\
(12.2-70.0)\end{array}$ & $\begin{array}{l}90.0 \pm 144.7 \\
(10.0-170.2)\end{array}$ & $\begin{array}{l}69.6 \pm 73.7 \\
(27.0-112.1)\end{array}$ & $\begin{array}{l}187.2 \pm 434.4 \\
(-53.4-427.8)\end{array}$ \\
\hline $\mathrm{M}_{24}$ & $\begin{array}{l}30.9 \pm 27.2 \\
(15.2-46.6)\end{array}$ & $\begin{array}{l}33.2 \pm 18.0 \\
(12.3-43.1)\end{array}$ & $\begin{array}{l}34.5 \pm 47.4 \\
(7.2-62.0)\end{array}$ & $\begin{array}{l}73.9 \pm 144.5 \\
(-6.1-154.0)\end{array}$ & $\begin{array}{l}75.0 \pm 73.4 \\
(32.6-117.4)\end{array}$ & $\begin{array}{l}154.7 \pm 378.8 \\
(-55.0-364.5)\end{array}$ \\
\hline
\end{tabular}

Group 1: before incision; Group 2: after incision, $M_{0}$ : before incision, $M_{3}, M_{6}, M_{12} M_{24}: 3,6,12$, and $24 \mathrm{~h}$ after surgical incision; without statistic difference between groups, Mann-Whitney test.

\section{DISCUSSION}

Hysterectomy was chosen because this procedure provokes intense pain stimulus during the postoperative period and afferent stimulus may be blocked with epidural drugs. The duration of surgery was similar in both groups and, therefore, the time for evaluation of the patient was also similar. General anesthesia was maintained with agents that do not have preemptive analgesic effect. A patient was excluded from Group 1 because she received a drug that was not allowed according to the protocol.

In the present study there was no reduction of intensity of postoperative pain with epidural infusion of $\mathrm{S}(+)$-ketamine and bupivacaine before surgery when compared with the same injection administered after the beginning of the surgical stimulus. Even though a significant difference in pain scores was not observed and the number of patients was small, the score was lower in Group 1 in all evaluated moments. Those data lead us to mention a tendency for improved analgesia when the solution was administered before the surgical incision. At M12, pain intensity was lower in Group 1 than in Group 2, which confirms this tendency, but is not enough to support a preemptive effect.

An analgesic effect was not obtained despite the epidural administration of drugs being considered efficient to reduce intensity of acute postoperative pain ${ }^{14}$. The epidural solution consisted of a combination of a local anesthetic and $\mathrm{S}(+)$ ketamine because these drugs work through different mechanisms with more intense analgesic effect. The volume of the anesthetic solution may have been insufficient to prevent alterations in the central nervous system resulting from the deleterious stimulus generated by the surgery.

General anesthesia was maintained with agents that do not have preemptive analgesic effect. Although there are many studies investigating preemptive analgesia, the methods employed by most researchers are considered inappropriate. Many studies were not double-blinded or patients were not randomized. In other studies, patients did not receive the same analgesia before and after the surgical incision ${ }^{15,16}$, or the analgesic was compared with saline solution administered before the surgical incision ${ }^{15}$, rendering an inaccurate evaluation. In addition to that, researchers did not consider the sensitivity induced by the inflammatory response within the immediate postoperative period ${ }^{16,17}$.

A protocol of preemptive analgesia suggested by McQuay was used in this study, in which the effect on postoperative pain is observed with the drug administered before and after surgical incision in the same dose and by the same route ${ }^{18}$.

A systematic review concluded that the preemptive analgesic effect depends on the selected analgesic technique. One study demonstrated an evident preemptive effect with epidural analgesia, reducing pain intensity and consumption of complementary analgesics, thus increasing the time to request the first complementation ${ }^{19}$. Other authors also obtained reduction of intensity of postoperative pain by administering ketamine before and during surgery ${ }^{20,21}$. Nevertheless, they did not obtain an improved analgesic effect with ketamine when administered before incision or after surgery ${ }^{22,23}$.

Antagonists of NMDA receptors like ketamine may reduce central sensitivity and hyperalgesia ${ }^{3,7-10,24}$. Ketamine could be effective to attenuate cytokines during surgery and improve recovery ${ }^{15,25}$.

This study investigated pro-inflammatory (IL-6, TNF- $\alpha$ ) and anti-inflammatory (IL-10) cytokines to check their concentrations with trauma and epidural drugs. Concentrations of interleukins were evaluated 3 hours after surgical incision, since production of cytokines is observed within 2-4 hours after tissue injury ${ }^{26}$. Epidural $\mathrm{S}(+)$-ketamine before or after surgical incision did not promote different plasmatic concentrations of IL-6, TNF- $\alpha$ or IL-10. However, IL-6 and IL-10 levels were significantly lower in Group 1 in almost all moments.

Finally, the epidural injection of $25 \mathrm{mg}$ of $\mathrm{S}(+)$-ketamine before the incision reduced the pain intensity only 12 hours after surgery and did not alter the production of cytokines. The maintenance of $\mathrm{S}(+)$-ketamine during postoperative period seems to be an interesting proposal to be tested. 


\section{REFERÊNCIAS / REFERENCES}

1. Rocha APC, Kraychete DC, Lemonica L et al. - Dor: aspectos atuais da sensibilização periférica e central. Rev Bras Anestesiol, 2007;57(1):94-105.

2. Watkins LR, Maier SF, Goehler LE - Immune activation: the role of pro-inflammatory cytokines in inflammation, illness responses and pathological pain states. Pain, 1995;63:289-302.

3. Wang SZ, Chen Y, Lin HY et al. - Comparison of surgical stress response to laparoscopic and open radical cystectomy. World J Urol, 2010;28(4):451455.

4. Watkins LR, Milligan ED, Maier SF - Glial proinflammatory cytokines mediate exaggerated pain states: implications for clinical pain. Adv Exp Med Biol, 2003;521:1-21.

5. Celerier E, Rivat $\mathrm{C}$, Jun $\mathrm{Y}$ et al. - Long-lasting hyperalgesia induced by fentanyl in rats: preventive effect of ketamine. Anesthesiology, 2000;92(2):465472.

6. Warncke T, Stubhaug A, Jørum E - Preinjury treatment with morphine or ketamine inhibits the development of experimentally induced secondary hyperalgesia in man. Pain, 2000;86:293-303.

7. Kissin I, Bright CA, Bradley EL Jr. - The effect of ketamine on opioid-induced acute tolerance: can it explain reduction of opioid consumption with ketamine-opioid analgesic combinations? Anesth Analg, 2000;91:14831488 .

8. Laulin JP, Maurette P, Corcuff JB et al. - The role of ketamine in preventing fentanyl-induced hyperalgesia and subsequent acute morphine tolerance. Anesth Analg, 2002;94(5):1263-1269.

9. Joly V, Richebe P, Guignard B et al. - Remifentanil-induced postoperative hyperalgesia and its prevention with small-dose ketamine. Anesthesiology, 2005;103(1):147-155.
10. Yamakura T, Sakimura K, Shimoji K - The stereoselective effects of ketamine isomers on heteromeric N-methyl-D-aspartate receptor channel. Anesth Analg, 2000;91:225-229.

11. Lahtinen $\mathrm{P}$, Kokki H, Hakala $\mathrm{T}$ et al. $-\mathrm{S}(+)$-ketamine as an analgesic adjunct reduces opioid consumption after cardiac surgery. Anesth Analg, 2004;99(5):1295-1301.

12. Almenrader N, Passariello M, D'Amico G et al. - Caudal additives for postoperative pain management in children: $\mathrm{S}(+)$-ketamine and neostigmine. Paediatr Anaesth, 2005;15(2):143-147.

13. Kuiken SD, van den Berg SJ, Tytgat GN et al. - Oral S(+)-ketamine does not change visceral perception in health. Dig Dis Sci, 2004;49(11-12):17451751.

14. Ryu HG, Lee CJ, Kim YT et al. - Preemptive low-dose epidural ketamine for preventing chronic postthoracotomy pain: a prospective, double-blinded, randomized, clinical trial. Clin J Pain, 2011;27(4):304-308.

15. Bong CL, Samuel M, Ng JM et al. - Effects of preemptive epidural analgesia on post-thoracotomy pain. J Cardiothorac Vasc Anesth, 2005;19(6):786-793.

16. Lavandhomme P, De Kock M, Waterloos H - Intraoperative epidural analgesia combined with ketamine provides effective preventive analgesia in patients undergoing major digestive surgery. Anesthesiology, 2005;103(4):681683.

17. Møiniche S, Kehlet H, Dahl JB - A qualitative and quantitative systematic review of preemptive analgesia for postoperative pain relief. Anesthesiology, 2002;96:725-741.

18. Katz J - Pre-emptive analgesia: importance of timing. Can J Anaesth, 2001;48:105-114.

19. Kissin I - Study design to demonstrate clinical value of preemptive analgesia: is the commonly used approach valid? Reg Anesth Pain Med, 2002;27:242244.

20. Ong KSO, Lirk P, Seymour RA et al. - The efficacy of preemptive analgesia for acute postoperative pain management: a meta-analysis. Anesth Analg, 2005; 100:757-773.

21. Lahtinen $\mathrm{P}$, Kokki H, Hakala $\mathrm{T}$ et al. $-\mathrm{S}(+)$-ketamine as an analgesic adjunct reduces opioid consumption after cardiac surgery. Anesth Analg, 2004;99(5):1295-1301.

22. Jaksch W, Lang S, Reichhalter R et al. - Perioperative small-dose S(+)ketamine has no incremental beneficial effects on postoperative pain when standard-practice opioid infusions are used. Anesth Analg, 2002;94:981-986.

23. Castro FE, Garcia JBS - Analgesia preemptiva com S (+)cetamina e bupivacaína peridural em histerectomia abdominal. Rev Bras Anestesiol, 2005;55(1):28-39.

24. Lin E, Calvano SE, Lowry SF - Inflammatory cytokines and cell response in surgery. Surgery 2000;127(2):117-126.

25. Kawasaki C, Kawasaki T, Ogata M et al. - Ketamine isomers suppress superantigen-induced proinflammatory cytokine in human whole blood. Can J Anaesth, 2001;48:819-823.

26. Naito Y, Tamai S, Shingu K et al. - Responses of plasma adrenocorticotropic hormone, cortisol, and cytokines during and after upper abdominal surgery. Anesthesiology, 1992;77:426-431. 